\title{
EVALUATING THE BEST POLYETHYLENE GLYCOL AS SOLID DISPERSION CARRIER BY TAKING ETORICOXIB AS A MODEL DRUG
}

\author{
HEMANTH A $^{1}$, HINDUSTAN ABDUL AHAD ${ }^{2 *}$, DEVANNA ${ }^{2}$ \\ ${ }^{1}$ Department of Pharmaceutics, Research Scholar JNTUA, Ananthapuramu, Andhra Pradesh, India. ${ }^{2}$ Department of Pharmaceutics, \\ JNTUA-OTPRI, Ananthapuramu, Andhra Pradesh, India. Email: abdulhindustan@gmail.com
}

Received: 12 October 2018, Revised and Accepted: 20 November 2018

\section{ABSTRACT}

Objective: The main objective of the current research is focused in discovering the best polyethylene glycol (PEG) as solid dispersion carrier using etoricoxib (ECB) as a model drug.

Methods: Varieties of PEG, namely PEG - 3350, PEG - 4000, PEG - 6000, PEG - 8000, and PEG - 20000, were evaluated as a carrier for making ECB solid dispersions. ECB:PEG was taken in the ratios of 1:1, 1:2,1:4, and 1:6. The solid dispersions were prepared by microwave fusion method and compressed using 8 station tablet compression machine. The fabricated solid dispersion tablets were tested for physicochemical characteristics and drug release rates. The release of ECB from the prepared solid dispersions was further analyzed kinetically using the first order and Hixson-Crowell's plots.

Results: All the solid dispersion batches were shown satisfactory physicochemical characteristics. ECB solid dispersion batches with PEG - 6000 showed good solubility in distilled water (up to $2.29 \pm 0.01 \mu \mathrm{g} / \mathrm{ml}$ ) and in $0.1 \mathrm{~N} \mathrm{HCl}$ (up to $2.18 \pm 0.01 \mu \mathrm{g} / \mathrm{ml}$ ) when compared with ECB alone $(0.21 \pm 0.01 \mu \mathrm{g} / \mathrm{ml}$ and $0.32 \pm 0.01 \mu \mathrm{g} / \mathrm{ml})$. The prepared solid dispersions with PEG 6000 are shown good ECB release.

Conclusion: Among PEG carriers, PEG - 6000 was found to be the best carrier for increasing the solubility and release rate of ECB form the solid dispersions compared to PEG - 3350, PEG - 4000, PEG - 8000, and PEG - 20000.

Keywords: Etoricoxib, Polyethylene glycol, Solid dispersions, Evaluation.

(C) 2019 The Authors. Published by Innovare Academic Sciences Pvt Ltd. This is an open access article under the CC BY license (http://creativecommons. org/licenses/by/4. 0/) DOI: http://dx.doi.org/10.22159/ajpcr.2019.v12i3.30251

\section{INTRODUCTION}

The industrial pharmacist makes so many trials with the aim to increase the solubility of poorly water-soluble drugs in an inexpensive way. Among the different techniques of increasing solubility, solid dispersion technique was attaining the fame [1].

Etoricoxib (ECB) is a nonsteroidal drug used in dealing with all the varieties of pain and arthritic inflammation. ECB is a poorly watersoluble drug with $92 \%$ protein binding and poor bioavailability $[2,3]$.

The present exploration was to increase the solubility of ECB by making solid dispersions using polyethylene glycol (PEG) carriers [4-8], namely PEG - 3350, PEG - 4000, PEG - 6000, PEG - 8000, and PEG - 20000 and finding out the best polymer among them. The solid dispersions were prepared by microwave melting method.

\section{MATERIALS AND METHODS}

Materials

ECB was procured from Yarrow Chemicals. PEG - 3350, PEG - 4000, PEG - 6000, PEG - 8000, and PEG - 20000 were obtained from Amrutha Organics, Hyderabad. Microcrystalline cellulose, talc, and magnesium stearate were procured from Colorcon, India.

\section{Methods}

\section{Compatibility studies}

Stability studies

Physical remarks of drug and excipients were studied by taking ECB and excipients in 1:1 ratio and compatibility studied at stressed storage conditions, i.e., at a temperature of $40^{\circ} \mathrm{C}$ and $\mathrm{RH}$ of $75 \%$ in environment control chamber [9] (Classic Scientific India, Mumbai) was performed.
Hygroscopic studies

The hygroscopic study of ECB was done under 33, 53, and 75\% RH for 4 days and the weight gain was studied [10]. These studies were performed in triplicates.

\section{Solubility studies}

ECB was tested for solubility in $0.1 \mathrm{~N} \mathrm{HCl}$, water, $\mathrm{pH} 4.5$ acetate buffer, pH 6.8 phosphate buffer, and pH 7.4 phosphate buffer [11].

\section{Fabrication of solid dispersions}

Solid dispersions with different drug:polymer ratios, from 1:1, 1:2, 1:4, and $1: 6 \mathrm{w} / \mathrm{w}$, were prepared using a microwave-induced fusion method. ECB and PEG 3350 were weighed in the ratio 1:1 and mixed gently for 5 min using a mortar and pestle. A fixed amount (i.e., $2 \mathrm{~g}$ ) of the mixture was subjected to microwave radiation for different durations $(3,4,5$, and $6 \mathrm{~min}$ ) at a constant power of $590 \mathrm{~W}$ in a microwave reactor (CATA-2R, Catalyst Systems, Pune, India). Similarly, mixtures of other ratios (from $1: 2,1: 4$, and $1: 6 \mathrm{w} / \mathrm{w}$ ) were prepared. Only one beaker was placed at a time inside the microwave oven. Then, the beakers containing the samples were maintained at room temperature for the samples to solidify. The solid dispersions were collected and placed in a glass desiccator for $24 \mathrm{~h}$, and then, the product was pulverized using a mortar and pestle. The pulverized powders were passed through an $80 \#$ sieve. Same procedure is adopted using PEG - 4000, PEG - 6000, PEG - 8000, and PEG - 20000 carriers. The various formulae of ECB with PEG are shown in Table 1.

\section{Flow properties}

The fabricated solid dispersions were evaluated for micromeritic properties $[12,13]$.

Preparation of tablets containing the solid dispersion

The prepared tablets with solid dispersions equivalent to $60 \mathrm{mg}$ of ECB were prepared by direct compression method [14] after mixing with the 
required amount of different ingredients as shown in Table 2 using 8 station tablet compression machine (Karnavati Engineering, Ahmedabad, India)

\section{Evaluation of solid dispersions of ECB}

The following parameters were tested for ECB solid dispersions [15-18].

\section{Morphological characteristics}

In this study, tablets were tested for size and shape.

\section{Thickness}

Tablets were evaluated for their thickness using Vernier Calipers (Qumos Enterprises, Mumbai, India). These trails were made in triplicates.

Table 1: Drug(ECB):carrier(PEG) ratios in various formulations

\begin{tabular}{lll}
\hline Drug: carrier & Ratio & Formulation name \\
\hline ECB: PEG-3350 & $1: 1$ & EPEG3-1 \\
& $1: 2$ & EPEG3-2 \\
& $1: 4$ & EPEG3-3 \\
& $1: 6$ & EPEG3-4 \\
ECB: PEG-4000 & $1: 1$ & EPEG4-1 \\
& $1: 2$ & EPEG4-2 \\
& $1: 4$ & EPEG4-3 \\
& $1: 6$ & EPEG4-4 \\
ECB: PEG-6000 & $1: 1$ & EPEG6-1 \\
& $1: 2$ & EPEG6-2 \\
& $1: 4$ & EPEG6-3 \\
& $1: 6$ & EPEG6-4 \\
ECB: PEG-8000 & $1: 1$ & EPEG8-1 \\
& $1: 2$ & EPEG8-2 \\
& $1: 4$ & EPEG8-3 \\
& $1: 6$ & EPEG8-4 \\
ECB: PEG-20000 & $1: 1$ & EPEG20-1 \\
& $1: 2$ & EPEG20-2 \\
& $1: 4$ & EPEG20-3 \\
& $1: 6$ & EPEG20-4 \\
\hline
\end{tabular}

Table 2: Formulation of a tablet containing solid dispersions

\begin{tabular}{ll}
\hline Ingredients & $\begin{array}{l}\text { Quantity per } \\
\text { tablet(mg) }\end{array}$ \\
\hline Solid dispersions equivalent to 60 mg of ECB & 125 \\
Lactose & 50 \\
Starch & 15 \\
Microcrystalline cellulose & 50 \\
Magnesium stearate & 5 \\
Talc & 5 \\
The weight of the tablets & 250 \\
\hline
\end{tabular}

Hardness

The force of fracture was recorded using Monsanto tablet hardness tester (Vinsyst Technologies, Mumbai). These tests were performed in triplicates.

\section{Uniformity in weight}

A total of 20 tablets from each formulation were weighed individually using an electronic digital balance (Citizen, CY-104, Mumbai) and calculated the average weight and compared with the individual tablet weights. From this, percentage weight difference was calculated and then checked for IP specifications (limit $\pm 7.5 \%$ of average weight).

\section{Friability}

It is the occurrence in which tablet surfaces are injured when subjected to physical tremor or erosion. This test was performed using Roche Friabilator. 20 tablets were weighed before the test $\left(\mathrm{W}_{\text {initis }}\right)$ and moved into a friabilator. The equipment was run at a speed of $25 \mathrm{rpm}$ for the

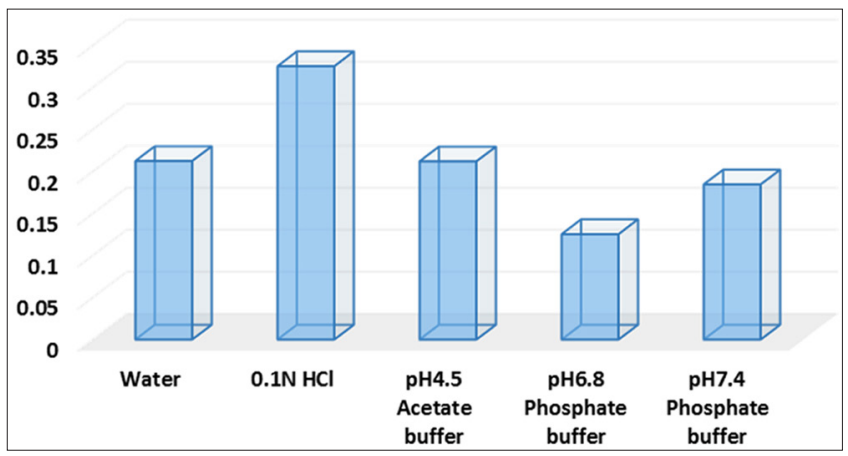

Fig. 1: Solubility of etoricoxib at various media

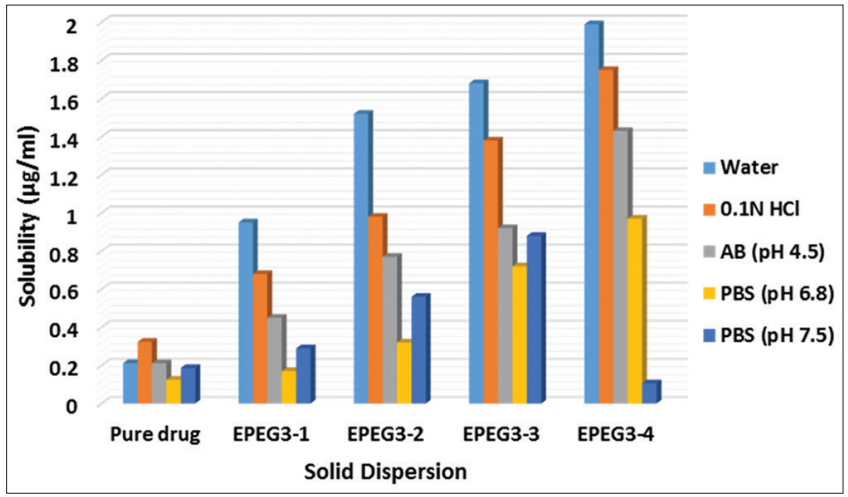

Fig. 2: Solubility of etoricoxib and solid dispersions with PEG - 3350 in various media

Table 3: ECB excipients(1:1) compatibility study physical observations

\begin{tabular}{|c|c|c|c|c|c|c|c|}
\hline \multirow[t]{3}{*}{ Binary mixture } & \multirow[t]{3}{*}{ Initial } & \multicolumn{6}{|c|}{ Storage condition } \\
\hline & & \multicolumn{3}{|c|}{ Room temperature } & \multicolumn{3}{|c|}{$40^{\circ} \mathrm{C} / 75 \% \mathrm{RH}$} \\
\hline & & 10 days & 20 days & 30 days & 10 days & 20 days & 30 days \\
\hline Etoricoxib & White to off-white powder & NCC & NCC & NCC & NCC & NCC & NCC \\
\hline$E+P E G-3350$ & White waxy powder & NCC & NCC & NCC & NCC & NCC & NCC \\
\hline$E+P E G-4000$ & White waxy powder & NCC & NCC & NCC & NCC & NCC & NCC \\
\hline$E+P E G-6000$ & White waxy powder & NCC & NCC & NCC & NCC & NCC & NCC \\
\hline E+PEG-20000 & White waxy powder & NCC & NCC & NCC & NCC & NCC & NCC \\
\hline E+Lactose & Off-white powder & NCC & NCC & NCC & NCC & NCC & NCC \\
\hline $\mathrm{E}+$ Starch & Off-white powder & NCC & NCC & NCC & NCC & NCC & NCC \\
\hline $\mathrm{E}+\mathrm{MCC}$ & Off-white powder & NCC & NCC & NCC & NCC & NCC & NCC \\
\hline $\mathrm{E}+\mathrm{MS}$ & Off-white powder & NCC & NCC & NCC & NCC & NCC & NCC \\
\hline E+Talc & Off-white powder & NCC & NCC & NCC & NCC & NCC & NCC \\
\hline
\end{tabular}

E-Etoricoxib, PEG: Polyethylene glycol, MCC: Microcrystalline cellulose, MS: Magnesium stearate, ECB: Etoricoxib 
period of 4 min and the final weight of tablets $\left(\mathrm{W}_{\text {final }}\right)$ was determined. The percentage friability was then measured by the following equation:

$\mathrm{F}=\frac{\mathrm{W} \text { initial }-\mathrm{W} \text { final }}{\mathrm{W} \text { initial }} \times 100$

Table 4: Hygroscopicity data(ECB)

\begin{tabular}{llll}
\hline Time interval & \multicolumn{3}{l}{ \% weight change } \\
\cline { 2 - 4 } & $\mathbf{3 3 \%} \mathbf{R H}$ & $\mathbf{5 3 \%} \mathbf{R H}$ & $\mathbf{7 5 \%} \mathbf{R H}$ \\
\hline Day 1 & 0.00 & 0.0 & 0.0 \\
Day 2 & 0.00 & $0.01 \pm 0.001$ & $0.02 \pm 0.001$ \\
Day 4 & 0.00 & $0.01 \pm 0.001$ & $0.01 \pm 0.001$ \\
Equilibrium RH & \multicolumn{3}{|}{} \\
$\begin{array}{l}\text { Day 0 } \\
\text { Day 4 }\end{array}$ & $0.101 \pm 0.002$ & $0.115 \pm 0.003$ & $0.117 \pm 0.002$ \\
Inference & $0.113 \pm 0.001$ & \\
\hline All values mentioned as mean \pm SD, the number of trials(n=3), ECB: Etoricoxib
\end{tabular}

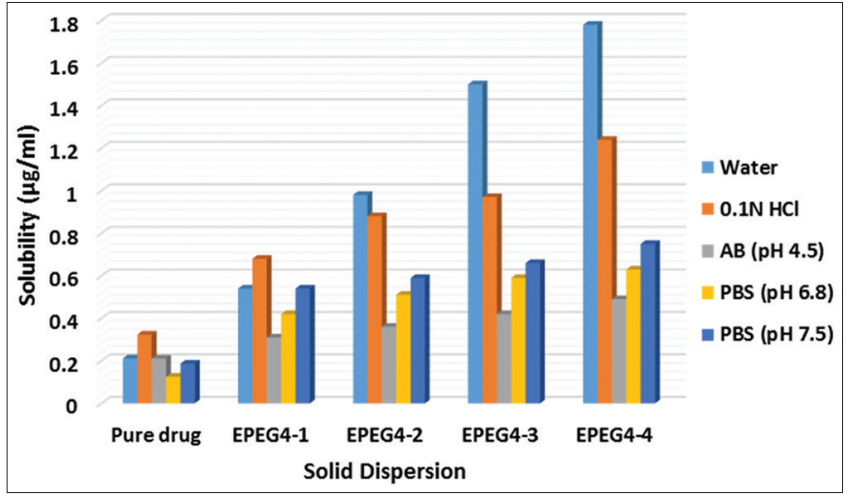

Fig. 3: Solubility of etoricoxib and solid dispersions with PEG - 4000 in various media

Table 5: Flow character specifications

\begin{tabular}{|c|c|c|c|c|c|}
\hline \multirow[t]{2}{*}{ Formulation } & \multicolumn{5}{|l|}{ Flow properties } \\
\hline & Angle of repose $\left({ }^{\circ}\right)$ & LBD & TBD & CI & HR \\
\hline EPEG3-1 & $25.21 \pm 0.04$ & $0.135 \pm 0.01$ & $0.144 \pm 0.01$ & $6.250 \pm 0.03$ & $1.066 \pm 0.03$ \\
\hline EPEG3-2 & $29.33 \pm 0.05$ & $0.369 \pm 0.02$ & $0.399 \pm 0.03$ & $7.518 \pm 0.02$ & $1.081 \pm 0.01$ \\
\hline EPEG3-3 & $34.21 \pm 0.04$ & $0.659 \pm 0.03$ & $0.677 \pm 0.03$ & $2.658 \pm 0.01$ & $1.027 \pm 0.02$ \\
\hline EPEG3-4 & $25.21 \pm 0.02$ & $0.658 \pm 0.01$ & $0.691 \pm 0.04$ & $4.775 \pm 0.02$ & $1.050 \pm 0.03$ \\
\hline EPEG4-1 & $26.33 \pm 0.01$ & $0.941 \pm 0.03$ & $0.985 \pm 0.07$ & $4.467 \pm 0.02$ & $1.046 \pm 0.01$ \\
\hline EPEG4-2 & $28.45 \pm 0.08$ & $0.286 \pm 0.01$ & $0.303 \pm 0.03$ & $5.610 \pm 0.04$ & $1.059 \pm 0.01$ \\
\hline EPEG4-3 & $29.21 \pm 0.09$ & $0.385 \pm 0.02$ & $0.432 \pm 0.02$ & $10.876 \pm 0.02$ & $1.122 \pm 0.03$ \\
\hline EPEG4-4 & $29.04 \pm 0.06$ & $0.365 \pm 0.02$ & $0.401 \pm 0.03$ & $8.977 \pm 0.02$ & $1.098 \pm 0.01$ \\
\hline EPEG6-1 & $30.25 \pm 0.04$ & $0.285 \pm 0.01$ & $0.298 \pm 0.01$ & $4.362 \pm 0.03$ & $1.045 \pm 0.03$ \\
\hline EPEG6-2 & $29.21 \pm 0.01$ & $0.654 \pm 0.03$ & $0.668 \pm 0.04$ & $2.095 \pm 0.01$ & $1.021 \pm 0.02$ \\
\hline EPEG6-3 & $27.25 \pm 0.03$ & $0.256 \pm 0.01$ & $0.287 \pm 0.01$ & $10.801 \pm 0.07$ & $1.121 \pm 0.03$ \\
\hline EPEG6-4 & $25.09 \pm 0.02$ & $0.748 \pm 0.02$ & $0.795 \pm 0.02$ & $5.911 \pm 0.045$ & $1.062 \pm 0.03$ \\
\hline EPEG8-1 & $27.27 \pm 0.05$ & $0.458 \pm 0.01$ & $0.521 \pm 0.03$ & $12.092 \pm 0.02$ & $1.137 \pm 0.01$ \\
\hline EPEG8-2 & $26.21 \pm 0.04$ & $0.136 \pm 0.01$ & $0.142 \pm 0.01$ & $4.225 \pm 0.03$ & $1.044 \pm 0.01$ \\
\hline EPEG8-3 & $26.37 \pm 0.09$ & $0.195 \pm 0.01$ & $0.213 \pm 0.01$ & $8.450 \pm 0.02$ & $1.092 \pm 0.04$ \\
\hline EPEG20-1 & $30.54 \pm 0.06$ & $0.365 \pm 0.01$ & $0.407 \pm 0.02$ & $10.319 \pm 0.05$ & $1.115 \pm 0.03$ \\
\hline EPEG20-2 & $28.45 \pm 0.02$ & $0.458 \pm 0.02$ & $0.489 \pm 0.03$ & $6.339 \pm 0.02$ & $1.067 \pm 0.01$ \\
\hline EPEG20-3 & $29.35 \pm 0.04$ & $0.526 \pm 0.04$ & $0.536 \pm 0.03$ & $1.865 \pm 0.01$ & $1.019 \pm 0.01$ \\
\hline EPEG20-4 & $27.97 \pm 0.05$ & $0.956 \pm 0.07$ & $0.978 \pm 0.03$ & $2.249 \pm 0.02$ & $1.023 \pm 0.03$ \\
\hline
\end{tabular}

LBD: Loose bulk density, TBD: Tapped bulk density, CI: Carr's index, HR: Hausner's ratio, All values mentioned as mean \pm SD; the number of trials(n=3)

Table 6: Physical characteristics of prepared solid dispersions

\begin{tabular}{|c|c|c|c|c|c|c|}
\hline \multirow[t]{2}{*}{ Formulation } & \multicolumn{6}{|c|}{ Physical parameters } \\
\hline & $\begin{array}{l}\text { Thickness } \\
\text { (mm) }\end{array}$ & $\begin{array}{l}\text { Hardness } \\
\left(\mathrm{cm}^{2}\right)\end{array}$ & $\begin{array}{l}\text { Uniformity of } \\
\text { weight(mg) }\end{array}$ & Friability (\%) & Yield(\%) & Assay $(\%)$ \\
\hline EPEG3-1 & $4.5 \pm 0.02$ & $4.5 \pm 0.01$ & $253.1 \pm 0.03$ & $0.51 \pm 0.05$ & $97.5 \pm 0.06$ & $98.6 \pm 2.33$ \\
\hline EPEG3-2 & $4.5 \pm 0.08$ & $5.2 \pm 0.05$ & $254.3 \pm 0.01$ & $0.41 \pm 0.02$ & $98.3 \pm 0.05$ & $99.4 \pm 0.01$ \\
\hline EPEG3-3 & $4.6 \pm 0.05$ & $7.3 \pm 0.01$ & $250.2 \pm 0.02$ & $0.33 \pm 0.01$ & $99.6 \pm 0.06$ & $98.9 \pm 0.06$ \\
\hline EPEG3-4 & $4.51 \pm 0.01$ & $5.3 \pm 0.04$ & $251.2 \pm 0.01$ & $0.36 \pm 0.01$ & $99.8 \pm 0.06$ & $97.6 \pm 5.24$ \\
\hline EPEG4-1 & $4.53 \pm 0.02$ & $4.5 \pm 0.02$ & $255.1 \pm 0.03$ & $0.51 \pm 0.08$ & $92.1 \pm 0.06$ & $96.3 \pm 0.95$ \\
\hline EPEG4-2 & $4.50 \pm 0.03$ & $5.2 \pm 0.02$ & $250.9 \pm 0.01$ & $0.17 \pm 0.01$ & $95.3 \pm 0.06$ & $99.2 \pm 2.38$ \\
\hline EPEG4-3 & $4.51 \pm 0.01$ & $6.3 \pm 0.07$ & $252.3 \pm 0.01$ & $0.52 \pm 0.05$ & $94.6 \pm 0.06$ & $100.9 \pm 6.35$ \\
\hline EPEG4-4 & $4.53 \pm 0.07$ & $5.3 \pm 0.01$ & $253.8 \pm 0.02$ & $0.25 \pm 0.02$ & $96.8 \pm 0.06$ & $97.6 \pm 0.09$ \\
\hline EPEG6-1 & $4.50 \pm 0.02$ & $4.5 \pm 0.03$ & $250.5 \pm 0.01$ & $0.44 \pm 0.05$ & $97.2 \pm 0.06$ & $98.3 \pm 0.09$ \\
\hline EPEG6-2 & $4.51 \pm 0.05$ & $5.2 \pm 0.02$ & $250.1 \pm 0.03$ & $0.85 \pm 0.08$ & $97.5 \pm 0.06$ & $99.0 \pm 0.01$ \\
\hline EPEG6-3 & $4.53 \pm 0.09$ & $6.7 \pm 0.01$ & $254.2 \pm 0.01$ & $0.53 \pm 0.02$ & $96.3 \pm 0.06$ & $102.1 \pm 0.01$ \\
\hline EPEG6-4 & $4.50 \pm 0.08$ & $8.3 \pm 0.01$ & $252.2 \pm 0.02$ & $0.25 \pm 0.02$ & $96.9 \pm 0.06$ & $99.2 \pm 0.08$ \\
\hline EPEG8-1 & $4.51 \pm 0.01$ & $4.5 \pm 0.03$ & $250.3 \pm 0.01$ & $0.15 \pm 0.01$ & $97.8 \pm 0.06$ & $96.5 \pm 0.95$ \\
\hline EPEG8-4 & $4.51 \pm 0.06$ & $5.3 \pm 0.02$ & $250.5 \pm 0.01$ & $0.25 \pm 0.08$ & $97.3 \pm 0.06$ & $98.2 \pm 0.15$ \\
\hline EPEG20-1 & $4.52 \pm 0.02$ & $4.5 \pm 0.02$ & $250.3 \pm 0.01$ & $0.54 \pm 0.01$ & $98.2 \pm 0.06$ & $100.1 \pm 0.08$ \\
\hline EPEG20-2 & $4.50 \pm 0.08$ & $5.9 \pm 0.07$ & $251.2 \pm 0.01$ & $0.62 \pm 0.02$ & $97.6 \pm 0.06$ & $97.3 \pm 0.15$ \\
\hline EPEG20-3 & $4.51 \pm 0.05$ & $6.3 \pm 0.01$ & $250.1 \pm 0.05$ & $0.53 \pm 0.08$ & $94.1 \pm 0.06$ & $98.5 \pm 0.09$ \\
\hline EPEG20-4 & $4.51 \pm 0.01$ & $5.3 \pm 0.01$ & $252.1 \pm 0.01$ & $0.63 \pm 0.04$ & $97.3 \pm 0.06$ & $97.9 \pm 0.81$ \\
\hline
\end{tabular}

All values mentioned as mean \pm SD; the number of trials $(n=3)$ 
Yield

The percentage recovery of formulated solid dispersion was resolute after complete removal of moisture. Thus, percentage recovery calculation involves the weight of dried solid dispersion to sum of the weight of drug and pharmaceuticals required for the formulation.

$\%$ Yield $=\frac{\text { Actual weight of the solid dispersions }}{\text { Total weight of drug and excipients }} \times 100$

\section{Uniformity of drug content}

Five tablets from each batch were taken and weighed and powdered in crushed in mortar and pestle. A weight equal to $60 \mathrm{mg}$ of ECB was dissolved in $100 \mathrm{ml}$ of $0.1 \mathrm{~N} \mathrm{HCl}(\mathrm{pH} \mathrm{1.2)}$. From this, $0.2 \mathrm{ml}$ sample was withdrawn and diluted to $10 \mathrm{ml}$ with $0.1 \mathrm{~N} \mathrm{HCl}$. The absorbance was determined [19] at $233 \mathrm{~nm}$ with double-beam UV-visible spectrophotometer (Lab India, Mumbai). Content uniformity was calculated from ECB standard graph.

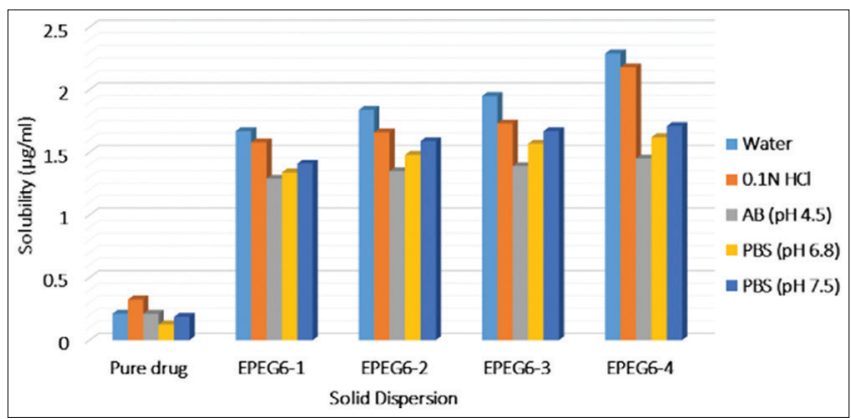

Fig. 4: Solubility of etoricoxib and solid dispersions with PEG - 6000 in various media

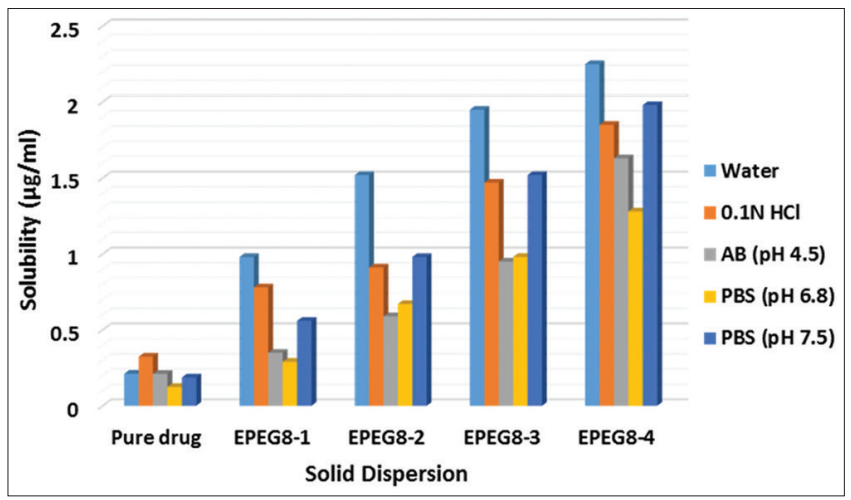

Fig. 5: Solubility of etoricoxib and solid dispersions with PEG - 8000 in various media

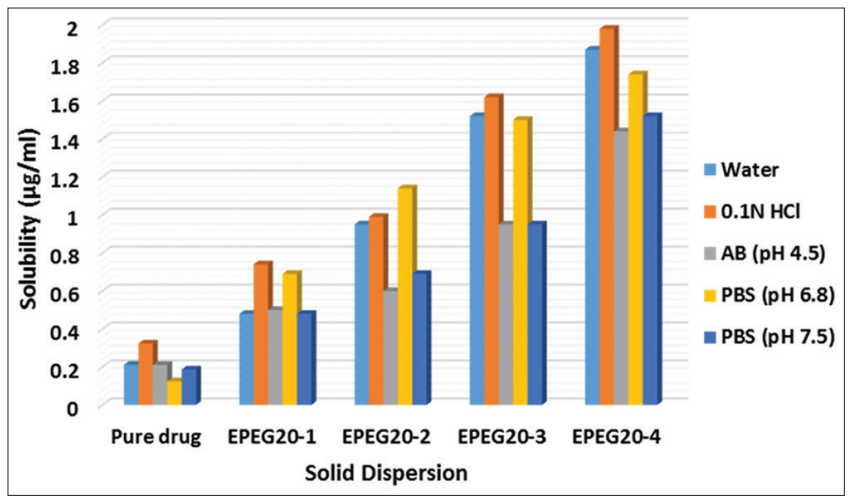

Fig. 6: Solubility of etoricoxib and solid dispersions with PEG - 20000 in various media
ECB calibration curve

The process of determining ECB by UV spectrophotometer at $233 \mathrm{~nm}$ was standardized and the drug was found to obey Beer-Lambert's law in $2-12 \mu \mathrm{g} / \mathrm{ml}$ concentration [20].

Dissolution rate/in vitro drug release

The dissolution specifications were as below [21].

Table 7: Concentration versus absorbance values for the estimation of ECB

\begin{tabular}{ll}
\hline Concentration $(\mu \mathrm{g} / \mathrm{ml})$ & Absorbance \\
\hline 2 & $0.125 \pm 0.0013$ \\
4 & $0.318 \pm 0.0011$ \\
6 & $0.473 \pm 0.0052$ \\
8 & $0.668 \pm 0.0013$ \\
10 & $0.851 \pm 0.0062$ \\
\hline All values mentioned as mean \pm SD; number of trials(n=3), ECB: Etoricoxib
\end{tabular}

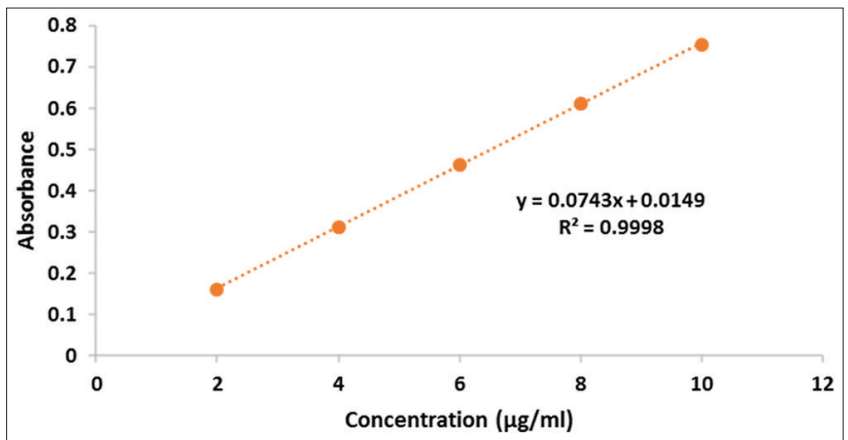

Fig. 7: Calibration curve for the estimation of etoricoxib

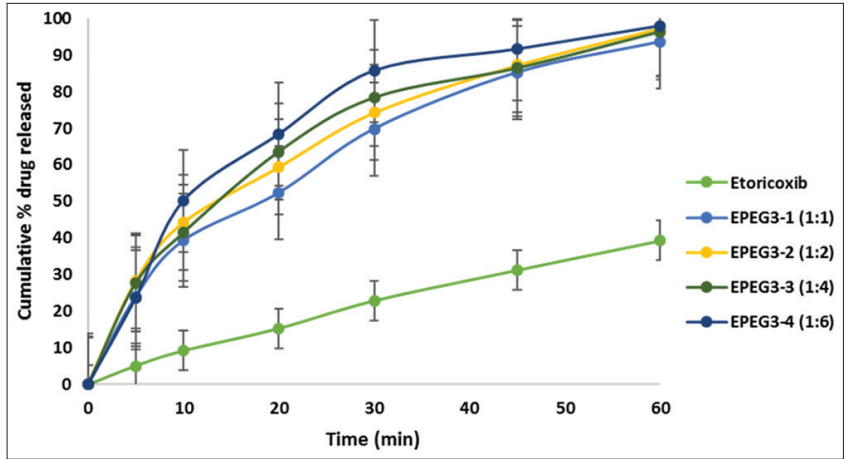

Fig. 8: In vitro drug dissolution plots of etoricoxib and PEG - 3350 solid dispersions

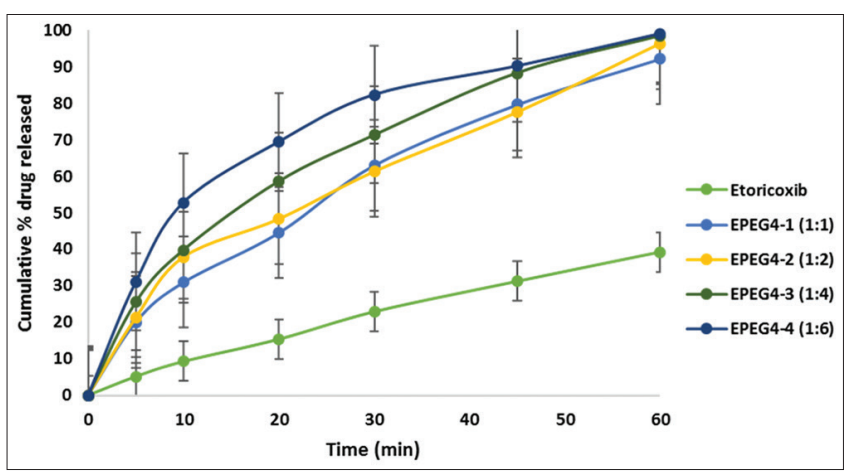

Fig. 9: In vitro drug dissolution plots of etoricoxib and PEG - 4000 solid dispersions 
- Apparatus used: USP XXIII dissolution test apparatus (Lab India, Thane, India)

- Dissolution medium: $0.1 \mathrm{~N} \mathrm{HCl}$

- The volume of dissolution medium: $900 \mathrm{ml}$

- Temperature: $37 \pm 0.5^{\circ} \mathrm{C}$

- The speed of basket paddle: $50 \mathrm{rpm}$

- Sampling intervals: 5 min

- Sample withdraws: $10 \mathrm{ml}$

- Absorbance measured: $233 \mathrm{~nm}$.

\section{Kinetic modeling of drug release}

The mechanism of the drug release was analyzed and rate kinetics of the dosage form was obtained as $[22,23]$ :

- Cumulative percentage drug released versus time (zero-order plots)

- Log cumulative percentage drug remaining versus time (first-order plots)

- Cube root of drug remaining versus time (Hixson-Crowell's plots).

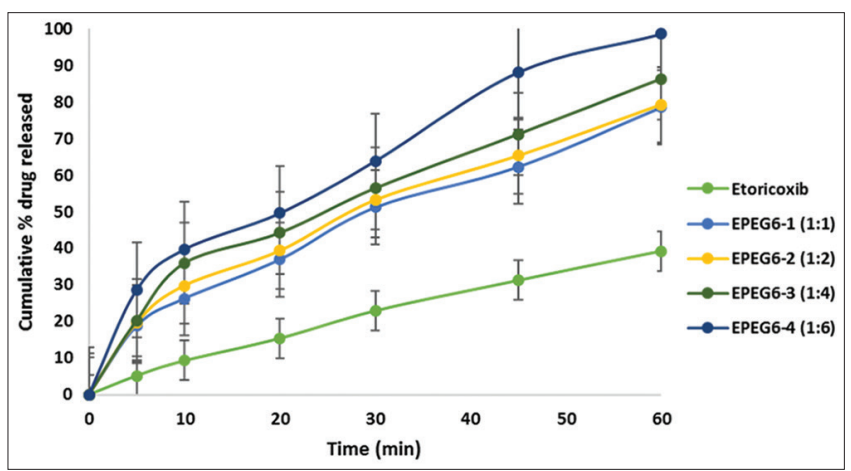

Fig. 10: In vitro drug dissolution plots of etoricoxib and PEG - 6000 solid dispersions

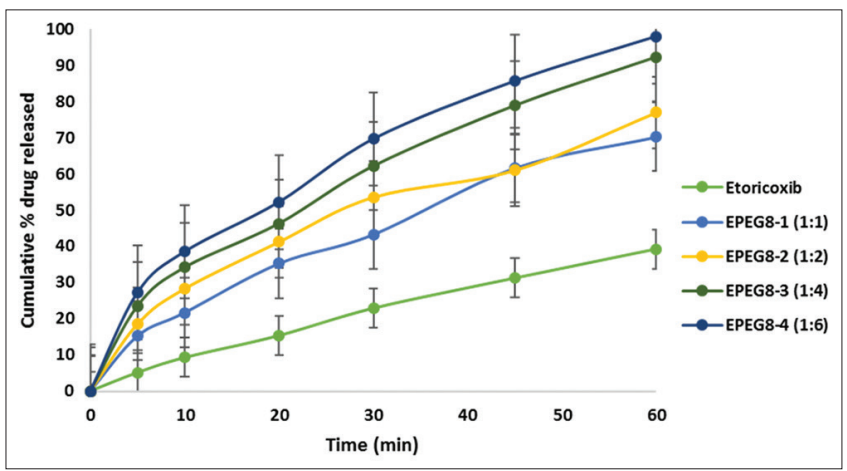

Fig. 11: In vitro drug dissolution plots of etoricoxib and PEG - 8000 solid dispersions

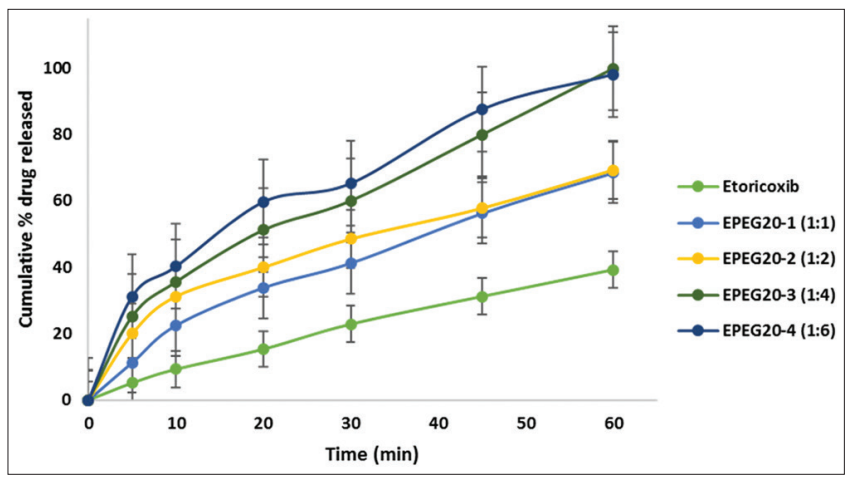

Fig. 12: In vitro drug dissolution plots of etoricoxib and PEG - 20000 solid dispersions
Accelerated stability studies of ECB solid dispersions

The evaluated ECB solid dispersions were then subjected to stability studies for a period of 3 months under stressed storage conditions [24].

\section{RESULTS}

The compatibility study revealed that ECB was found to compatible with the excipients used and they are tabulated in Table 3.

Physical observations of excipients compatibility study at stressed storage conditions

The hygroscopic study of ECB at room temperature $\left(25 \pm 2^{\circ} \mathrm{C}\right)$ and humidity conditions is shown in Table 4.

The solubility of ECB pure drug in various solvents is shown in Fig. 1.

The fabricated ECB solid dispersions were characterized for flow properties and the values are shown in Table 5.

Evaluation of ECB solid dispersions (in tablet dosage form)

The fabricated ECB solid dispersions tablets were observed for physicochemical characteristics and they are tabulated in Table 6 .

\section{Solubility studies of ECB solid dispersions}

The solubility of ECB and prepared ECB solid dispersions are shown in Figs. 2-6.

Calibration curve of ECB

The calibration curve of ECB is shown in Table 7 and Fig. 7.

Dissolution data of ECB from PEG solid dispersions

The dissolution of prepared tablets was found good in formulations containing ECB:PEG ratios 1:4. These are shown in Figs. 8-12.

\section{Kinetic modeling of drug release}

The drug release mechanism from prepared tablets formulations was determined by kinetic treatment of in vitro drug dissolution data. The

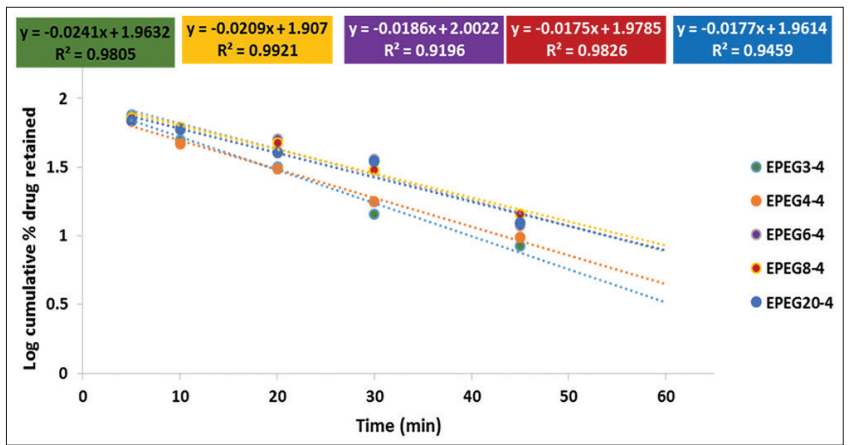

Fig. 13: First-order plots for EPEG tablets

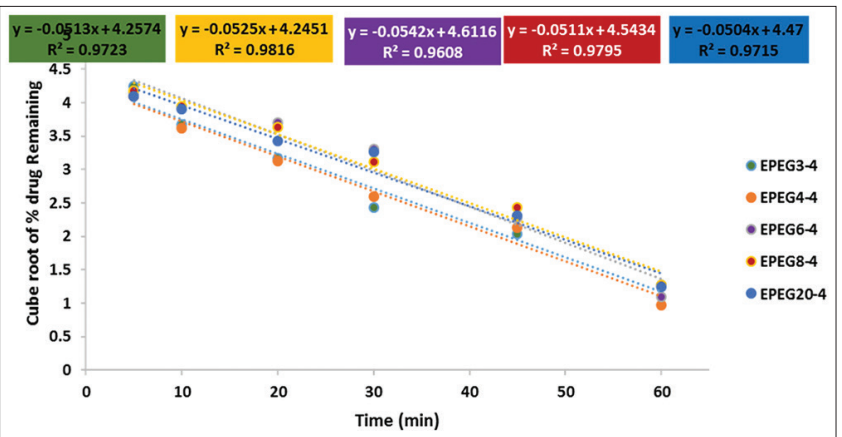

Fig. 14: Hixson-Crowell's plots for EPEG-4 tablets 
correlation (r2) values from the different kinetics equations were shown in Figs. 13 and 14.

\section{DISCUSSION}

The compatibility study revealed that ECB was found to compatible with the excipients used. The hygroscopicity study of the drug used ECB indicates that drug is non-hygroscopic, as the percentage weight increase in the samples at the study was $<0.2 \%$.

ECB pure drug showed good solubility in $0.1 \mathrm{~N} \quad \mathrm{HCl}$ $(0.325 \pm 0.0011 \mu \mathrm{g} / \mathrm{ml})$ and water $(0.212 \pm 0.0021 \mu \mathrm{g} / \mathrm{ml})$. The solubility of ECB was found to be $0.212 \pm 0.0023,0.125 \pm 0.0051$, and $0.185 \pm 0.0065 \mu \mathrm{g} / \mathrm{ml}$ in $\mathrm{pH} 4.5$ acetate buffer, $\mathrm{pH} 6.8$ phosphate buffer, and $\mathrm{pH} 7.4$ phosphate buffer, respectively. The solubility data indicate that ECB has very poor solubility. The fabricated ECB solid dispersions were found to have excellent flow properties.

The fabricated ECB solid dispersion tablets were observed to have a uniform in size, shape, off-white in color, and odorless with smooth surface. The prepared tablets were found to have a uniform thickness $(4.5 \mathrm{~mm})$ and weight. The loss on friability was $<1 \%$ and the hardness was more than $4 \mathrm{~kg} / \mathrm{cm}^{2}$ indicating that the prepared tablets having good mechanical strength. The percentage yield of solid dispersions was found to good (>90\%) and the drug content was also found to be uniform.

The solubility of prepared tablets was found good in distilled water and $0.1 \mathrm{~N} \mathrm{HCl}$. All the ECB solid dispersion batches with PEG - 3350 showed good solubility in distilled water (up to $1.99 \pm 0.01 \mu \mathrm{g} / \mathrm{ml}$ ) and $0.1 \mathrm{~N} \mathrm{HCl}$ (up to $1.75 \pm 0.02 \mu \mathrm{g} / \mathrm{ml}$ ). All the ECB solid dispersion batches with PEG - 4000 showed good solubility in distilled water (up to $1.78 \pm 0.01 \mu \mathrm{g} / \mathrm{ml}$ ) and $0.1 \mathrm{~N} \mathrm{HCl}$ (up to $1.24 \pm 0.01 \mu \mathrm{g} / \mathrm{ml}$ ).

All the ECB solid dispersion batches with PEG - 6000 showed good solubility in distilled water (up to $1.21 \pm 0.01 \mu \mathrm{g} / \mathrm{ml}$ ) and $0.1 \mathrm{~N} \mathrm{HCl}$ (up to $0.81 \pm 0.01 \mu \mathrm{g} / \mathrm{ml}$ ).

All the ECB solid dispersion batches with PEG - 80000 showed good solubility in distilled water (up to $2.25 \pm 0.09 \mu \mathrm{g} / \mathrm{ml}$ ), in PBS ( $\mathrm{pH} 7.5$ ) (up to $1.98 \pm 0.05 \mu \mathrm{g} / \mathrm{ml}$ ), and in $0.1 \mathrm{~N} \mathrm{HCl}$ (up to $1.85 \pm 0.03 \mu \mathrm{g} / \mathrm{ml}$ ).

All the solid dispersion batches of PEG - 20000 showed good solubility in $0.1 \mathrm{~N} \mathrm{HCl}$ (up to $1.98 \pm 0.07 \mu \mathrm{g} / \mathrm{ml}$ ) and distilled water (up to $1.87 \pm 0.01 \mu \mathrm{g} / \mathrm{ml}$ ). The dissolution of prepared tablets was found good in all the formulations containing ECB.

The drug release mechanism from prepared tablets formulations was determined by kinetic treatment of in vitro drug dissolution data. The correlation $\left(\mathrm{r}^{2}\right)$ values from the different kinetics equation revealed that the drug release from the prepared solid dispersions was found to follow different models, but the best fit model was selected. First order and Hixson Crowell's plots. The optimized formulation (EPEG6-4) when subjected to accelerate stability studies, it retained its drug content, hardness, and cumulative percentage drug release.

\section{CONCLUSION}

This investigation was performed to the best PEG carrier for preparing solid dispersions by taking ECB as a model drug. The formulation EPEG6-4 in the ratios 1:6 was found to have good solubility and drug dissolution characteristics. Moreover, among the PEG - 3350, PEG - 4000, PEG - 6000, PEG - 8000, and PEG - 20000, polyethylene glycol was found to be the best PEG among the tested one as solid dispersion carrier

\section{AUTHORS' CONTRIBUTIONS}

All authors read and approved the final manuscript.

\section{CONFLICTS OF INTEREST}

The authors declare that they have no conflicts of interest.

\section{REFERENCES}

1. Chiou WL, Riegelman S. Pharmaceutical applications of solid dispersion systems. J Pharm Sci 1971;60:1281-302.

2. Takemoto JK, Reynolds JK, Remsberg CM, Vega-Villa KR, Davies NM. Clinical pharmacokinetic and pharmacodynamic profile of etoricoxib. Clin Pharmacokinet 2008;47:703-20.

3. Agrawal NG, Porras AG, Matthews CZ, Rose MJ, Woolf EJ, Musser BJ, et al. Single-and multiple-dose pharmacokinetics of etoricoxib, a selective inhibitor of cyclooxygenase-2, in man. J Clin Pharmacol 2003;43:268-76.

4. Kahovec J, Fox RB, Hatada K. Nomenclature of regular single-strand organic polymers. Pure Appl Chem 2002;74:1921-56.

5. Chen SL, Cai SR, Deng L, Zhang XH, Luo TD, Peng JJ, et al. Efficacy and complications of polyethylene glycols for treatment of constipation in children: A meta-analysis. Medicine (Baltimore) 2014;93:e65.

6. Dannenfelser RM, He H, Joshi Y, Bateman S, Serajuddin AT. Development of clinical dosage forms for a poorly water soluble drug I: Application of polyethylene glycol-polysorbate 80 solid dispersion carrier system. J Pharm Sci 2004;93:1165-75.

7. Wang X, Michoel A, Van den Mooter G. Study of the phase behavior of polyethylene glycol 6000-itraconazole solid dispersions using DSC. Int J Pharm 2004;272:181-7.

8. Law D, Schmitt EA, Marsh KC, Everitt EA, Wang W, Fort JJ, et al. Ritonavir-PEG 8000 amorphous solid dispersions: In vitro and in vivo evaluations. J Pharm Sci 2004;93:563-70.

9. Otsuka M, Onoe M, Matsuda Y. Hygroscopic stability and dissolution properties of spray-dried solid dispersions of furosemide with eudragit. J Pharm Sci 1993;82:32-8.

10. Poovi G, Rajpriyadarsini S, Uma S, Vinothini R. Development, characterization and solubility enhancement of comparative dissolution study of second generation of solid dispersions and microspheres for poorly water soluble drug. Asian J Pharm Sci 2015;10:433-41

11. Lachman L, Lieberman HA, Kanig JL. The Theory and Practice of Industrial Pharmacy. Philadelphia, PA: Lea and Febiger; 1987. p. 317-8.

12. Martin A. Physical Pharmacy. $4^{\text {th }}$ ed. Maryland, USA: Lippincott Williams and Wilkins; 1991. p. 423.

13. Jachowicz R, Niirnberg E, Hoppe R. Solid dispersions of oxazepam. Int J Pharm 1993;99:321-5.

14. Sheu MT, Yeh CM, Sokoloski TD. Characterization and dissolution of fenofibrate solid dispersion systems. Int J Pharm 1994;103:137-46.

15. United State Pharmacopoeial Convention. The United State Pharmacopoeia 24, NF 19. Rockville, M.D: United State Pharmacopoeial Convention, Asian Edi.; 2000. p. 1462-5, 1913-4.

16. Shashi KY, Veena M, Srinivas M. Solid dispersion technique to enhance the solubility and dissolution rate of aripiprazole by fusion method. Int J Pharm Pharm Sci 2016;8:187-92.

17. Gamal MM, Samar FG. Preparation and evaluation of rapidly dissolving tablets of raloxifene hydrochloride by ternary system formation. Int $\mathrm{J}$ Pharm Pharm Sci 2016;8:127-36.

18. Hindustan AA, Chitta SK, Ravindra BV, Harika B. Fabrication and in vitro evaluation of gliclazide Abelmoschus esculentus fruit mucilage prolonged release matrix tablets. J Pharm Res 2011;4:118-20.

19. Dalmora SL, Sangoi Mda S, da Silva LM, Macedo RO, Barth T. Validation of a capillary zone electrophoresis method for the comparative determination of etoricoxib in pharmaceutical formulations. J Sep Sci 2008;31:169-76.

20. Singh S, Mishra A, Verma A, Ghosh AK, Mishra AK. A simple ultraviolet spectrophotometric method for the determination of etoricoxib in dosage formulations. J Adv Pharm Technol Res 2012;3:237-40.

21. Modi A, Tayade P. Enhancement of dissolution profile by solid dispersion (kneading) technique. AAPS PharmSciTech 2006;7:68.

22. Korsmeyer RW, Gunny R, Doelker EM, Buri P, Peppas NA. Mechanisms of solute release from porous hydrophilic polymers. Int $\mathrm{J}$ Pharm 1983;15:25-35.

23. Higuchi T. Mechanism of sustained-action medication. Theoretical analysis of rate of release of solid drugs dispersed in solid matrices. J Pharm Sci 1963;52:1145-9.

24. Remunan C, Bretal M, Nunez A Bila JL. Accelerated stability of sustained release tablet prepared with gelucire. Int $\mathrm{J}$ Pharm 1992;80: 151-9. 